\section{Nauplius}

The Journal OF The Brazilian Crustacean Society

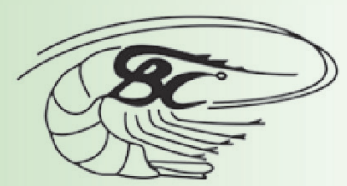

e-ISSN 2358-2936

www.scielo.br/nau www.crustacea.org.br

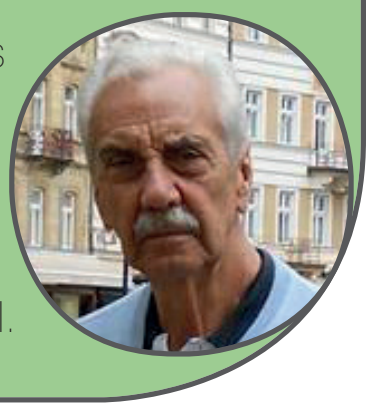

\title{
Infestation by the epibiont Octolasmis lowei in a portunid crab assemblage from a subtropical coast
}

Lylian Marcia da Silva-Inácio ${ }^{\top}$, Glauco Barreto de Oliveira Machado ${ }^{2}$, Monique D’Assunção Fortuna ${ }^{3}$, Fabio Henrique Carretero Sanches ${ }^{4}$ and Tânia Marcia Costa ${ }^{1}$

1 Laboratório de Ecologia e Comportamento Animal, Universidade Estadual Paulista (UNESP), Instituto de Biociências, Campus do Litoral Paulista (CLP). Praça Infante D. Henrique, s/nº, Parque Bitaru. 11330-900 São Vicente, São Paulo, Brazil. LMS-I E-mail: lylian_inacio@yahoo.com.br

TMC E-mail: costatm@clp.unesp.br

2 Pós-Graduação em Ecologia, Universidade Estadual de Campinas (UNICAMP). Avenida Bertrand Russell. 13083-970 Campinas, São Paulo, Brazil.

GBOM E-mail: gbomachado@gmail.com

3 Pós-Graduação em Biodiversidade Aquática, Universidade Estadual Paulista (UNESP), Instituto de Biociências, Campus do Litoral Paulista (CLP). Praça Infante D. Henrique, s/nº, Parque Bitaru. 11330-900 São Vicente, São Paulo, Brazil. MDF E-mail: mofortuna@gmail.com

4 Pós-Graduação em Ciências Biológicas (Zoologia), Universidade Estadual Paulista (UNESP), Instituto de Biociências, Campus de Botucatu. Rua Prof. Dr. Antonio Celso Wagner Zanin, s/no, Rubião Junior. 18618-689 Botucatu, São Paulo, Brazil. FHCS E-mail: fabiohcsanches@yahoo.com.br

ZOOBANK: http://zoobank.org/urn:lsid:zoobank.org:pub:0ADF105F-A101-4305A0C5-0CC8489BDE2D

\section{ABSTRACT}

We investigated the infestation by Octolasmis lowei Darwin, 1851 in branchial chambers of the portunid Achelous spinimanus (Latreille, 1819), Arenaeus cribrarius (Lamarck, 1818), Callinectes danae Smith, 1869, and Callinectes ornatus Ordway, 1863. We evaluated how infestation is related to host maturity, molt stage, carapace width and sex. The infestation probability increases with host carapace width, and infested crabs were more likely to be adults 
in intermolt stage. Infestation prevalence did not differ between sexes, except for C. ornatus, in which females had higher infestation than males. Infestation intensity was higher for males than females in A. cribrarius and A. spinimanus, while C. ornatus showed an opposite pattern. Association of $O$. lowei with portunid seems to be tightly related to the biological traits of its host. Some of these traits, such as host size, maturity and molt stage, are likely to affect infestation in a similar way for all host species, while the effect of other traits, such as sex identity, seems to vary among hosts. We suggest a deeper understanding of the factors driving host use by generalist epibionts such as $O$. lowei depends on investigating their occurrence on a variety of potential hosts, as well as performing manipulative studies to evaluate the factors driving host preferences by this epibiont.

\section{KEY WORDS}

Decapods, epibiosis, infestation patterns, stalked barnacle.

\section{INTRODUCTION}

In marine habitats dominated by soft bottoms, some benthic organisms have an important role in providing hard substrate for the settlement and growth of other species such as algae, barnacles and bryozoans (Jeffries et al., 1992; Wahl and Hay, 1995; Becker and Wahl, 1996; Key et al., 1999). In this epibionthost interaction, hosts can enhance access to food sources and optimize epibiont dispersal (review in Wahl, 1989). However, some hosts can be negatively affected (e.g. increase in weight and surface friction), which may cause reduced mobility (Dixon et al., 1981) depending on the number and species of epibionts. Among host organisms, marine benthic decapods have been extensively reported in sheltering epibionts (Abelló and Macpherson, 1992; Jeffries et al., 1992; Becker and Wahl, 1996; Key et al., 1999; Santos and Bueno, 2002; Cordeiro and Costa, 2010). Epibiont infestation in decapods is often related to the biological traits of these hosts, such as behavior, size, sex, maturity and molt stage (Abelló and Macpherson, 1992; Jeffries et al., 1992; Becker and Wahl, 1996; Key et al., 1999; Cordeiro and Costa, 2010).

The infraclass Cirripedia is a typical group of epibionts which occur in decapods (Abelló and Macpherson, 1992; Jeffries et al., 1992; Key et al., 1997; Costa et al., 2010). These sessile invertebrates are found attached to the carapace (Key et al., 1997; Costa et al., 2010) and branchial chambers of their hosts (Abelló and Macpherson, 1992; Jeffries et al., 1992; Santos and Bueno, 2002). Among cirripedians, the stalked barnacle of the genus Octolasmis Gray, 1825 is an exclusive epibiont, often found adhered to the gills of decapods such as lobsters (Jeffries et al., 1984; 1991) and crabs (Dinamani, 1964; Jeffries et al., 1982; Voris et al., 1994; Cordeiro and Costa, 2010). Usually, the host is not negatively affected by the epibiont, unless when there is a large number of the latter, which may cause negative effects in host gas exchanges (Wahl, 1989). In addition, Octolasmis species have a planktonic larval stage, followed by settlement and metamorphosis to adult form in the branchial chambers of their hosts, completing its life cycle during host intermolt stage (Walker, 1974; Gili et al., 1993; Jeffries and Voris, 1996).

Although infestation by the genus Octolasmis in decapods is well documented (Jeffries and Voris, 1983; Young, 1990; Shields, 1992; Walker, 2001; Santos and Bueno, 2002; Yan et al., 2004; Cordeiro and Costa, 2010; Costa et al., 2010; Farrapeira, 2010; Machado et al., 2013), few studies have attempted to simultaneously investigate the association of these epibionts in a variety of sympatric host species (Humes, 1941; Jeffries et al., 1982; Kumaravel et al., 2009; Machado et al., 2013). Such approach is important for understanding host usage range in epibionts, as well as to evaluate the effect of biological traits (e.g. maturity, size and sex) on infestation, which could improve our knowledge of the factors influencing epibiont-host interaction. In Brazil, the occurrence of Octolasmis lowei Darwin, 1851 has been reported in the branchial chambers of crabs from the families Aethridae, Epialtidae, Leucosiidae and Portunidae (Young, 1990; Santos and Bueno, 2002; Cordeiro and Costa, 2010; Costa et al., 2010; Machado et al., 2013). However, these findings are reported in different areas and for few host species per study. Herein, we evaluated the infestation of the stalked barnacle $O$. lowei in branchial chambers of four portunid species, investigating how infestation 
by this epibiont is related to host maturity, size, sex and molt stage.

\section{Material and Methods}

Portunid crabs were collected monthly in the Ubatuba bay, on the northern coast of the state of São Paulo, Brazil $\left(23^{\circ} 30^{\prime}\right.$ to $23^{\circ} 23^{\prime} S$; $45^{\circ} 05^{\prime}$ to $\left.44^{\circ} 47^{\prime} \mathrm{W}\right)$ from November 2001 to April 2002 (except December 2001). Sampling was carried out using an otter trawl towed by a commercial fishing boat, along transects parallel to the coastline, covering depths from 5 to 25 $\mathrm{m}$. We trawled 6 to 10 transects monthly, totalizing 43 transects. Samples were bagged and maintained frozen until analysis. Crabs were identified in accordance to Melo (1996). For each individual, maximum carapace width (CW in $\mathrm{mm}$ ) was measured, excluding lateral spines. Crabs were sexed based on abdomen shape (Williams, 1974) and the number of pleopods (Melo, 1996). Molt stage (intermolt or molt activity) was determined according to carapace consistency (Skinner, 1985). After removing the dorsal carapace, we inspected the branchial chambers in O. lowei using a stereo-microscope and determined maturity stage (adult or juvenile) based on gonad state (Costa and Negreiros-Fransozo, 1998).

For all host species, data analyses were restricted to adult crabs, since juveniles are unlikely to be infested (Machado et al., 2013). Only one juvenile (a female of Callinectes ornatus Ordway, 1863) was found to be infested, but it was excluded from the analysis. For each host species, we compared carapace width and proportion of individuals in intermolt stage between males and females applying Student's t test (assuming equal or unequal variances) and a Chi-squared test, respectively. Homogeneity of variance was verified by a Cochran test. Infestation (considering crab condition: infested or non-infested) was analyzed using logistic regression, with CW and sex as explanatory variables. Also, for each host, the effect of CW on infestation was tested in both sexes with a logistic regression and, from the resulting models, we estimated odd ratios of infestation (the ratio of the probability of being infested to the probability of not being infested) according to CW. Prevalence (\%) and intensity of infestation (number of epibionts per infested host) were compared between males and females using a Chisquared test and a generalized linear model (GLM), respectively. All GLM applied to the intensity of infestation comparisons among sexes were tested using Negative Binomial distribution. Statistical difference was considered when $\mathrm{p}<0.05$.

\section{ReSULTS}

A total of 1840 adult portunid crabs were sampled, represented by the following species: Achelous spinimanus (Latreille, 1819) $(\mathrm{N}=246)$, Arenaeus cribrarius (Lamarck, 1818) ( $\mathrm{N}=112)$, Callinectes danae Smith, $1869(\mathrm{~N}=164)$, and Callinectes ornatus $(\mathrm{N}=1318)$. Highest infestation prevalence by O. lowei was observed in C. danae (22.56\%) followed by A. cribrarius (13.39\%), C. ornatus (10.85\%) and $A$. spinimanus (8.13\%). Among infested host species, A. spinimanus showed higher infestation intensity values (11.1 \pm 16.4 epibionts/ind.) than those observed in $C$. ornatus (7.4 \pm 8.4$)$, C. danae $(3.3 \pm 3.2)$ and A. cribrarius (3.1 \pm 3.4$)$. Males had larger $\mathrm{CW}$ than females in all host species (A. cribrarius: $\mathrm{t}=3.204, \mathrm{df}=83.41, P=0.002 ; C$. danae: $\mathrm{t}=3.745, \mathrm{df}=26.06, P=0.001$; . ornatus: $\mathrm{t}=$ $15.523, \mathrm{df}=1092.8, P<0.0001)$, except in $A$. spinimanus $(\mathrm{t}=1.877, \mathrm{df}=244, P=0.062)$. Proportion of individuals in intermolt stage did not differ between sexes, in any of the host species (A. cribrarius: $\chi^{2}=0.620, P=0.431 ; C$. danae: $\chi 2=2.601, P=0.107$; C. ornatus: $\chi 2=2.019, P=$ 0.155 and $A$. spinimanus: $\chi 2=3.601, P=0.058$ ) (Tab. 1 ).

In A. cribrarius, C. ornatus and A. spinimanus, infestation (infested or non-infested) was affected by host CW and sex (Tab. 2); in A. cribrarius and $A$. spinimanus, the effect of sex was marginally significant; in C. danae, CW affected infestation in males only (Tab. 3). In all cases in which $C W$ affected infestation, it was observed that infestation probability increased with size (Fig. 1, Tab. 3). For example, for one-unit increase in size, males of $A$. cribrarius were 1.265 times (26.5\%) more likely to be infested.

Infestation prevalence did not differ between males and females in $A$. cribrarius $(\chi 2=0.002, P=0.968)$, C. danae $\left(\chi^{2}=0.329, P=0.566\right)$ and $A$. spinimanus $(\chi 2=0.791, P=0.374)$. In contrast, prevalence was higher for females than males in C. ornatus ( $\chi 2=$ 5.281, $P=0.022)$. Infestation intensity was higher in males than females in A. cribrarius (GLM, Deviance $=$ 6.441, d.f. $=1$, Residual deviance $=12.393, P=0.011$ ) and $A$. spinimanus (GLM, Deviance $=9.042$, d.f. $=1$, Residual deviance $=20.910, P=0.003)$. In C. ornatus, the pattern was opposite (GLM, Deviance $=3.975$, d.f. $=1$, Residual deviance $=149.48, P=0.046)$, while in $C$. 
Table 1. Descriptive variables of portunid crabs and Octolasmis lowei infestation by host species and sex $(\mathrm{M}=\mathrm{male} ; \mathrm{F}=\mathrm{female})$ : Number of individuals $(\mathrm{N})$, Carapace width (mean \pm standard deviation in $\mathrm{mm}$ ), Individuals in intermolt stage (\%), Prevalence of infestation (\%) and Intensity of infestation (mean \pm standard deviation). ${ }^{*}$ Indicates a significant difference between males and females $(P<0.05)$.

\begin{tabular}{|c|c|c|c|c|c|c|c|c|c|c|}
\hline \multirow{2}{*}{ Host species } & \multicolumn{2}{|c|}{$\mathrm{N}$} & \multicolumn{2}{|c|}{ Carapace width } & \multicolumn{2}{|c|}{ Intermolt (\%) } & \multicolumn{2}{|c|}{ Prevalence (\%) } & \multicolumn{2}{|c|}{ Intensity } \\
\hline & $\mathrm{M}$ & $\mathrm{F}$ & $\mathrm{M}$ & $\mathrm{F}$ & $\mathrm{M}$ & $\mathrm{F}$ & $\mathrm{M}$ & $\mathrm{F}$ & $\mathrm{M}$ & $\mathrm{F}$ \\
\hline A. cribrarius & 48 & 64 & $* 77.5 \pm 12.0$ & $70.9 \pm 8.9$ & 91.7 & 96.9 & 14.6 & 12.5 & $* 4.7 \pm 4.4$ & $1.6 \pm 1.1$ \\
\hline C. danae & 24 & 140 & $* 77.5 \pm 12.4$ & $67.7 \pm 7.6$ & 87.5 & 97.1 & 29.2 & 21.4 & $2.9 \pm 2.9$ & $3.4 \pm 3.3$ \\
\hline C. ornatus & 631 & 687 & ${ }^{*} 56.6 \pm 10.0$ & $49.4 \pm 6.2$ & 87.2 & 89.8 & ${ }^{*} 8.7$ & 12.8 & ${ }^{*} 5.9 \pm 7.4$ & $8.3 \pm 8.9$ \\
\hline A. spinimanus & 71 & 175 & $59.0 \pm 14.1$ & $63.2 \pm 16.1$ & 77.5 & 88.0 & 11.3 & 6.9 & ${ }^{*} 20.1 \pm 23.2$ & $5.0 \pm 5.0$ \\
\hline
\end{tabular}

Table 2. Analysis of deviance for logistic regression fitted to condition of infestation by Octolasmis lowei in each host species. Size and sex of crabs were used as explanatory variables.

\begin{tabular}{|c|c|c|c|c|c|}
\hline Source of variation & $D f$ & Deviance & Residual df & Residual deviance & $P\left(>\left|\chi^{2}\right|\right)$ \\
\hline \multicolumn{6}{|l|}{ A.cribrarius } \\
\hline NULL & - & - & 111 & 88.208 & - \\
\hline Size & 1 & 16.596 & 110 & 71.613 & $<0.001$ \\
\hline Sex & 1 & 3.887 & 109 & 67.725 & 0.049 \\
\hline Size X Sex & 1 & 0.428 & 108 & 67.298 & 0.513 \\
\hline \multicolumn{6}{|l|}{ C. danae } \\
\hline NULL & - & - & 163 & 175.12 & - \\
\hline Size & 1 & 0.350 & 162 & 174.78 & 0.554 \\
\hline Sex & 1 & 0.403 & 161 & 174.37 & 0.526 \\
\hline Size X Sex & 1 & 7.349 & 160 & 167.02 & 0.007 \\
\hline \multicolumn{6}{|l|}{ C. ornatus } \\
\hline NULL & - & - & 1317 & 905.10 & - \\
\hline Size & 1 & 18.169 & 1316 & 886.94 & $<0.001$ \\
\hline Sex & 1 & 27.115 & 1315 & 859.82 & $<0.001$ \\
\hline Size X Sex & 1 & 0.882 & 1314 & 858.94 & 0.348 \\
\hline \multicolumn{6}{|l|}{ A. spinimanus } \\
\hline NULL & - & - & 245 & 138.71 & - \\
\hline Size & 1 & 24.428 & 244 & 114.28 & $<0.001$ \\
\hline Sex & 1 & 4.266 & 243 & 110.02 & 0.039 \\
\hline Size X Sex & 1 & 2.605 & 242 & 107.41 & 0.107 \\
\hline
\end{tabular}

Table 3. Analysis of deviance for logistic regression fitted to condition of infestation by Octolasmis lowei. Odds ratio (OR) and 95\% confidence interval (CI) for males and females of host species.

\begin{tabular}{lccccc}
\hline Species & Sex & OR & $95 \%$ CI & Deviance & $P\left(>\left|\chi^{2}\right|\right)$ \\
\hline A. cribrarius & Female & 1.171 & $1.04-1.39$ & 7.045 & 0.008 \\
& Male & 1.265 & $1.09-1.60$ & 13.763 & $<.001$ \\
C. danae & Female & 0.969 & $0.92-1.02$ & 1.421 & 0.233 \\
& Male & 1.142 & $1.02-1.37$ & 6.012 & 0.014 \\
C. ornatus & Female & 1.069 & $1.03-1.11$ & 11.316 & $<.001$ \\
& Male & 1.098 & $1.06-1.14$ & 29.094 & $<.001$ \\
A. spinimanus & Female & 1.089 & $1.03-1.16$ & 10.853 & 0.001 \\
& Male & 1.211 & $1.09-1.44$ & 19.203 & $<0.001$ \\
\hline
\end{tabular}



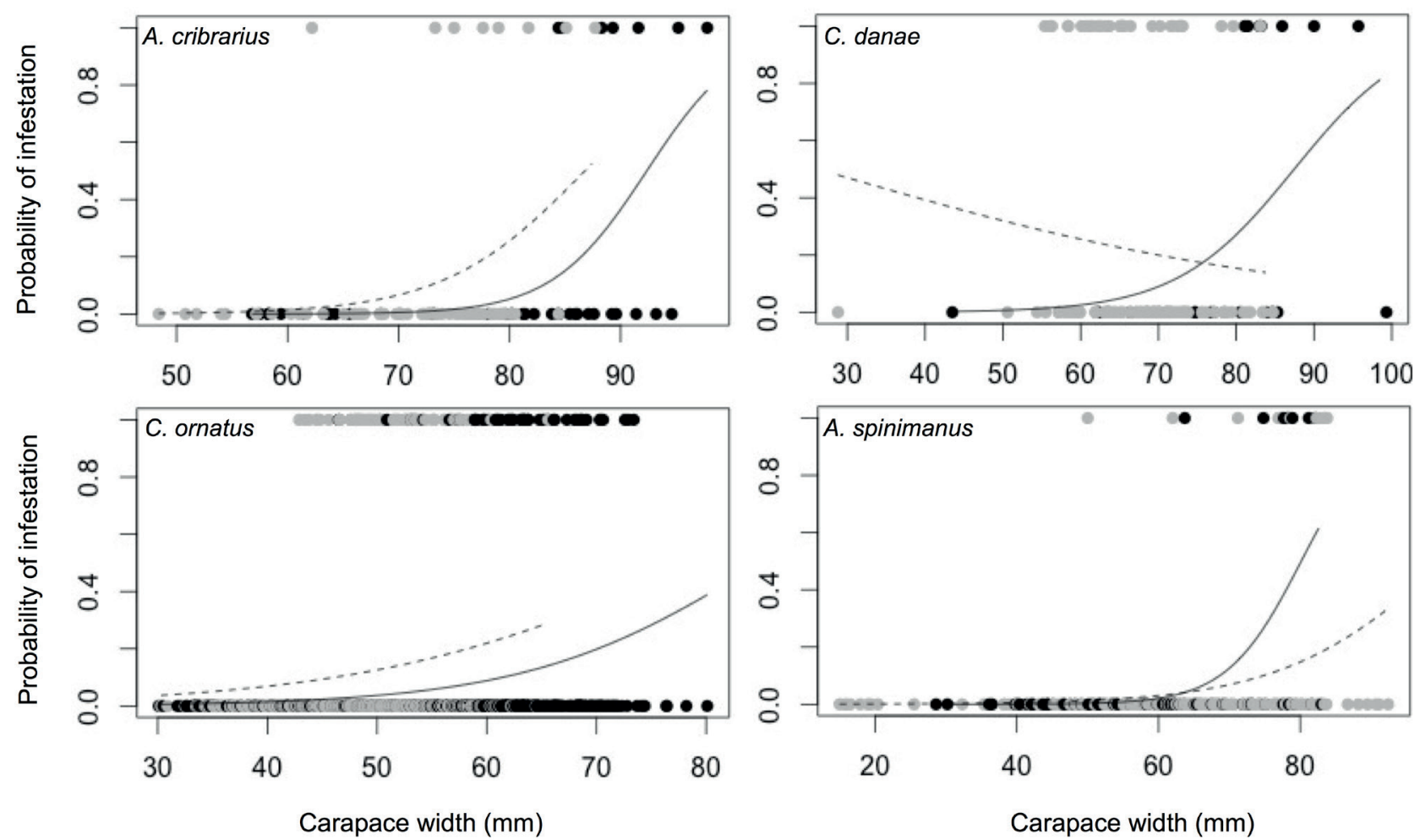

Figure 1. Relationship between probability of being infested by Octolasmis lowei and host size by sex. Gray solid circles = Female; Black solid circles = Male. For each species, solid circles on the top and bottom of graph represent the size of infested and no infested individuals, respectively. Solid and dashed lines represent the fitted model for males and females, respectively.

danae infestation intensity did not differ between sexes (GLM, Deviance $=0.219$, d.f. $=1$, Residual deviance $=34.837, P=0.640)$ (Tab. 1). Overall, infested crabs were in intermolt stage, except for two A. spinimanus individuals that were in pre-molt stage.

\section{Discussion}

Portunid crabs have an important role as hosts for $O$. lowei. Infestation by $O$. lowei in portunid crabs was affected by the biological traits of these hosts. We found the probability of infestation by $O$. lowei increased with host carapace width, regardless of host species, as well as that infested crabs were more likely to be adults in intermolt stage. Furthermore, although the prevalence of infestation was similar between females and males (except for C. ornatus), the intensity of infestation was influenced by sex for most host species. Overall, infestation by $O$. lowei seems to be restricted to a fraction of the host populations (i.e. adults in intermolt stage), which is in an agreement with other studies that reported epibiont infestation in decapods (Santos and Bueno, 2002; Costa et al., 2010; Machado et al., 2013).
Spatial availability can be a limiting factor for the success of sessile organisms (Connell, 1972). However, the interval during which such space is available is also vital for epibionts on living substrates (Gili et al., 1993). Since molting eliminates epibionts on the carapace surface and within the branchial chambers of crabs and other crustaceans (Walker, 1974; Jeffries and Voris, 1996), the interval between consecutive molting processes, or intermolt period, is often a constraint for epibiont success (Kuris, 1978; Jeffries and Voris, 1996). We found the probability of infestation by $O$. lowei in portunids crabs increases with host carapace width. Also, almost all infested crabs were adults in intermolt stage. These findings support the importance of temporal substrate availability for epibionts, since older and larger crabs molt less frequently than smaller individuals, and are thus more likely to be infested ( $\mathrm{Li}$ et al., 2014). Similar results have been reported for other decapods infested by Octolasmis spp. (Jeffries et al., 1992; Shields, 1992; Machado et al., 2013).

Molt frequency and spatial distribution have been suggested as to promote differences in epibiont 
infestation between sexes of decapods (Abelló and Macpherson, 1992; Key et al., 1997). For all host species, the proportion of individuals in intermolt stage did not differ between males and females. Since molt activity is related to infestation, such results support the lack of difference in infestation prevalence between sexes for all portunid crabs in the present study, except for C. ornatus, in which females had higher infestation prevalence than males. Also, for all host species, males had a larger carapace width than females. However, although a positive relationship was found between host size and probability of infestation for males and females of most host species, the differences in size between sexes alone are unlikely to explain the patterns of infestation prevalence observed for these species.

The differences in infestation prevalence between males and females of $C$. ornatus contrast with previous studies that reported higher infestation prevalence by O. lowei in males (Santos and Bueno, 2002; Machado et al., 2013). This may be explained by the differential spatial distribution between sexes of this portunid in the Ubatuba bay. Andrade et al. (2013) observed that males inhabit shallower waters, while females are more often found in depths between 15 and 20 $\mathrm{m}$. Our sampling was carried out in a wide range that included both male and female habitats (from 5 to 25 $\mathrm{m})$. It may be that the vulnerability of $C$. ornatus to the infestation by $O$. lowei is higher in deeper waters, where females occur more often. However, our sampling was not properly designed to address robust comparisons among depths and, thus, further studies are required to test if the infestation by $O$. lowei varies throughout a range of depths. In addition, Machado et al. (2013) observed higher infestation prevalence by $O$. lowei in females of $C$. danae than males, contrary to our results. A shorter sampling period ( 5 months) in comparison with other studies may be responsible for such singular results, since infestation can vary temporally. Costa et al. (2010) found that A. cribrarius presented a lower prevalence of infestation by $O$. lowei and other epibionts during winter. Since the relative contribution of each demographic category (males, non-ovigerous females, ovigerous females and juveniles) to the population of a crab species often varies temporally (Santos et al., 1995; Johnson and Perry, 1999; Carvalho and Couto, 2011; Andrade et al., 2013), these categories might have been represented differently in our sample when compared to those of previous studies, which may explain some divergences in results (e.g. infestation on ovigerous females tend to be higher than non-ovigerous females and males, probably because these females has longer intermolt periods; Costa et al., 2010).

The infestation intensity by $O$. lowei in our study differed between sexes for most host species, but in distinct ways. Males of Achelous spinimanus and Arenaeus cribrarius presented higher infestation intensity than females. In contrast, females of $C$. ornatus presented higher infestation intensity than males, while no difference was observed between sexes in $C$. danae. Such results suggest the mechanisms involved in avoiding and/or reducing infestation may vary between host sexes and species. For example, Cordeiro and Costa (2010) suggest that an efficient branchial cleaning by females of Libinia spinosa $\mathrm{H}$. Milne Edwards, 1834 may result in a lower intensity of infestation than that observed for males. However, this question remains unclear and, thus, further studies are required to explore the causes of inter-specific and sex differences in epibiont infestation. Furthermore, except for C. danae, the obtained results contrast with studies that reported a lack of difference in infestation intensity between sexes in portunid crabs (Santos and Bueno, 2002; Costa et al., 2010; Machado et al., 2013). Some divergences in results may be explained by many factors, such as: differences in sampling sites, depth and length among studies. Further studies considering a variety of spatial and temporal scales could contribute to elucidate such divergences.

Octolasmis species have been reported to have low specificity regarding the host use, occurring in a variety of host species (Jeffries et al., 1982; Jeffries and Voris, 1983; Shields, 1992; Walker, 2001; Yan et al., 2004; Kumaravel et al., 2009; Machado et al., 2013), which should be advantageous, since the availability of hard substrate is often a constraint for sessile organisms. In the present study, although $O$. lowei occurred in all portunid species sampled, the infestation by this epibiont seems to vary among their hosts. Both males and females of $A$. spinimanus had much higher intensity of infestation than any other host species, but an infestation prevalence that was comparable to those of other hosts (except C. danae). In this case, the abundance of $A$. spinimanus is unlikely to explain the higher infestation intensity, since this portunid species occurred in lower abundance than C. ornatus, 
which had lower infestation intensity. Such result may suggest certain degree of host preference by $O$. lowei towards $A$. spinimanus. In contrast, $C$. danae had the highest infestation prevalence, but lower infestation intensity, which indicates that although a higher proportion of individuals was infested, the average number of $O$. lowei per individual was low. The extent to which the occurrence of $O$. lowei in a variety of host species is related to the preference of this epibiont and/or is a constraint to other factors (e.g. availability of host) requires further investigation. Manipulative experiments with robust designs could improve our understanding about the factors driving the host species and sex preferences by $O$. lowei.

We found that biological traits of portunid crabs, such as carapace width and sex, influence infestation by $O$. lowei, which is in agreement with previous studies (Abelló and Macpherson, 1992; Jeffries et al., 1992; Shields, 1992; Key et al., 1997; Santos and Bueno, 2002; Machado et al., 2013). Some of these traits, such as carapace width, maturity and molt stage, seem to affect O. lowei infestation in a similar way for all host species. On the other hand, the effect of sex on infestation varied among host species. In this sense, we suggest a deeper understanding of the factors driving host use by generalist epibionts such as $O$. lowei depends on investigating their occurrence on a variety of potential hosts.

\section{ACKNOWLEDGEMENTS}

We would like to thank the personnel from Núcleo de Estudos em Biologia, Ecologia e Cultivo de Crustáceos(NEBECC - Unesp Botucatu) and Grupo de Pesquisa em Biologia de Crustáceos (CRUSTA - Unesp São Vicente) for helping with field and laboratory analyses. Also, we appreciate the valuable comments of two anonymous reviewers. This work was financially supported by São Paulo Research Foundation (FAPESP) (\# 98/07090-3 BIOTA Project, \# 02/09217-8 fellowship undergraduate Silva-Inácio ML and \# 01/00886-1 post-doctorate grant Costa TM).

\section{References}

Abelló, P. and Macpherson, E. 1992. Epibiosis and rhizocephalan infestation patterns in relation to the reproductive biology of Lithodes ferox (Filhol, 1885) (Anomura: Lithodidae). Journal of Crustacean Biology, 12(4): 561-570.
Andrade, L.S.; Fransozo, V.; Cobo, V.J.; Castilho, A.L.; Bertini, G.; and Fransozo, A. 2013. Ontogenetic distribution of Callinectes ornatus (Decapoda, Portunoidea) in southeastern Brazil. Ciencias Marinas, 39(4): 371-385.

Becker, K. and Wahl, M. 1996. Behaviour patterns as natural antifouling mechanisms of tropical marine crabs. Journal of Experimental Marine Biology and Ecology, 203(2): 245-258.

Carvalho, F.L. and Couto, E.D.C.G. 2011. Environmental variables influencing the Callinectes (Crustacea: Brachyura: Portunidae) species distribution in a tropical estuary - Cachoeira River (Bahia, Brazil). Journal of the Marine Biological Association of the United Kingdom, 91(4): 793-800.

Connell, J.H. 1972. Community interactions on marine rocky intertidal shores. Annual Review of Ecology and Systematics, 3: 169-192.

Cordeiro, C.A.M.M. and Costa, T.M. 2010. Infestation rates of the pedunculated barnacle Octolasmis lowei (Cirripedia: Poecilasmatidae) on the spider crab Libinia spinosa (Decapoda: Majoidea). Journal of Marine Biological Association of the United Kingdom, 90(2): 315-322.

Costa, T.M.; Christofoletti R.A. and Pinheiro, M.A.A. 2010. Epibionts on Arenaeus cribrarius (Brachyura, Portunidae) from Brazil. Zoologia, 27(3): 387-394.

Costa, T.M. and Negreiros-Fransozo, M.L. 1998. The reproductive cycle of Callinectes danae Smith, 1869 (Decapoda, Portunidae) in the Ubatuba region, Brazil. Crustaceana, 71(6): 615-627.

Dinamani, P. 1964. Variation in form, orientation and mode of attachment of the cirriped, Octolasmis stella (Ann.), symbiotic on the gills of lobster. The Journal of Animal Ecology, 33(2): 357-362.

Dixon, J.; Schroeter, S.C. and Kastendick. J. 1981. Effects of encrusting bryozoan, Membranipora membranacea, on the loss of blades and fronds by the giant kelp, Macrocystis pyrifera (Laminariales). Journal of Phycology, 17: 341-345.

Farrapeira, C.M.R. 2010. Shallow water Cirripedia of the northeastern coast of Brazil: the impact of life history and invasion on biogeography. Journal of Experimental Marine Biology and Ecology, 392(1): 210-219.

Gili, J.; Abelló, P. and Villanueva, R. 1993. Epibionts and intermoult duration in the crab Bathynectes piperitus. Marine Ecology Progress Series, 98: 107-113.

Humes, A.G. 1941. Notes on Octolasmis mülleri (Coker), a barnacle commensal on crabs. Transactions of the American Microscopical Society, 60(1): 101-103.

Jeffries, W.B. and Voris, H.K. 1983. The distribution, size, and reproduction of the pedunculate barnacle, Octolasmis mülleri (Coker, 1902), on the blue crab, Callinectes sapidus (Rathbun, 1896). Fieldiana Zoology, 16: 1-10.

Jeffries, W.B. and Voris, H.K. 1996. A subject-indexed bibliography of the symbiotic barnacles of the genus Octolasmis Gray, 1825 (Crustacea: Cirripedia: Poecilasmatidae). The Raffles Bulletin of Zoology, 44(2): 575-592. 
Jeffries, W.B.; Voris, H.K. and Poovachiranon, S .1992. Age of the mangrove crab Scylla serrata at colonization by stalked barnacles of the genus Octolasmis. The Biological Bulletin, 182(2): 188-194.

Jeffries, W.B.; Voris, H.K. and Yang, C.M. 1982. Diversity and distribution of the pedunculate barnacle Octolasmis in the seas adjacent to Singapore. Journal of Crustacean Biology, 2(4): 562-569.

Jeffries, W.B.; Voris, H.K. and Yang, C.M. 1984. Diversity and distribution of the pedunculate barnacle Octolasmis Gray, 1825, epizoic on the scyllarid lobster, Thenus orientalis. Crustaceana, 46(3): 300-308.

Jeffries, W.B.; Voris, H.K. and Yang, C.M. 1991. Species recognition among the pedunculate barnacles (Cirripedia: Thoracica) on the mangrove crabs, Scylla serrata. Raffles Bulletin of Zoology, 40(1): 83-92.

Johnson, D.R. and Perry, H.M. 1999. Blue crab larval dispersion and retention in the Mississippi Bight. Bulletin of Marine Science, 65(1): 129-149.

Key, M.M.; Volpe, J.; Jeffries, W.B. and Voris, H.K. 1997. Barnacle fouling of the blue crab Callinectes sapidus at Beaufort, North Carolina. Journal of Crustacean Biology, 17(3): 424-439.

Key, M.M.; Winston, J.E.; Volpe, J.W.; Jeffries, W.B. and Voris, H.K. 1999. Bryozoan fouling of the blue crab Callinectes sapidus at Beaufort North Carolina. Bulletin of Marine Science, 64(3): 513-533.

Kumaravel, K.; Ravichandran, S. and Rameshkumar, G. 2009. Distribution of barnacle Octolasmis on the gill region of some edible crabs. Academic Journal of Entomology, 2(1): 36-39.

Kuris, A.M. 1978. Life cycle, distribution and abundance of Carcinonemertes epialti, a nemertean egg predator of the shore crab, Hemigrapsus oregonensis, in relation to host size, reproduction and molt cycle. The Biological Bulletin, 154(1): 121-137.

Li, H.X.; Ma, L.S.; Yan, Y.; Yang, C.P. and Lin, C.X. 2014. First records of the epizoic barnacle Octolasmis bullata (Cirripedia: Thoracica: Poecilasmatidae) on the swimming crab Portunus sanguinolentus (Decapoda: Portunidae). Journal of Crustacean Biology, 34(1): 76-81.

Machado, G.B.O; Sanches, F.H.; Fortuna, M.D. and Costa, T.M. 2013. Epibiosis in decapod crustaceans by stalked barnacle Octolasmis lowei (Cirripedia: Poecilasmatidae). Zoologia (Curitiba), 30(3): 307-311.
Melo, G.A.S. 1996. Manual de identificação dos Brachyura (caranguejos e siris) do litoral brasileiro. São Paulo: Plêiade/ FAPESP. 603 p.

Santos, C. and Bueno, S.L.S. 2002. Infestation by Octolasmis lowei (Cirripedia: Poecilasmatidae) in Callinectes danae and Callinectes ornatus (Decapoda: Portunidae) from São Sebastião, Brazil. Journal of Crustacean Biology, 22(2): 241248.

Santos, S.; Negreiros-Fransozo, M.L. and Fransozo, A. 1995. Estructura poblacional de Portunus spinimanus Latreille, 1819 (Crustacea, Brachyura, Portunidae) en la Enseada de la Fortaleza, Ubatuba (SP). Revista de Investigaciones Marinas, 16(1-3): 37-43.

Shields, J.D. 1992. Parasites and symbionts of the crab Portunus pelagicus from Moreton Bay, Eastern Australia. Journal of Crustacean Biology, 12(1): 94-100.

Skinner, D.M. 1985. Molting and regeneration. p. 43-146. In: D.E. Bliss and L.H. Mantel (eds), The Biology of Crustacea. New York, Academic Press.

Voris, H.K.; Jeffries, W.B. and Poovachiranon, S. 1994. Patterns of distribution of two barnacle species on the mangrove crab, Scylla serrata. The Biological Bulletin, 187(3): 346-354.

Wahl, M. 1989. Marine epibiosis. I. Fouling and antifouling: some basic aspects. Marine Ecology Progress Series, 58: 175-189.

Wahl, M. and Hay, M. 1995. Associational resistance and shared doom: effects of epibiosis on herbivory. Oecologia, 102(3): 329-340.

Walker, G. 1974. The occurrence, distribution and attachment of the pedunculate barnacle Octolasmis mulleri (Coker) on the gills of crabs, particularly the blue crab, Callinectes sapidus Rathbun. The Biological Bulletin, 147(3): 678-689.

Walker, G. 2001. Some observations on the epizoic barnacle Octolasmis angulata within the branchial chambers of an Australian swimming crab. Journal of Crustacean Biology, 21(2): 450-455.

Williams M.J. 1974. The swimming crabs of genus Callinectes (Decapoda: Portunidae). Fisheries Bulletin, 72(3): 685-789.

Yan, Y.; Huang, L. and Miao S. 2004. Occurrence of the epizoic barnacle Octolasmis angulata on the crab Charybdis feriatus from Daya Bay, China. Journal of the Marine Biological Association of the United Kingdom, 84(3): 619-620.

Young, P.S. 1990. Lepadomorph cirripeds from Brazilian coast. I: families Lepadidae, Poecilasmatidae and Heteralepadidae. Bulletin Marine Science, 47(3): 641-655. 